Stinson, K. A., S. A. Campbell, J. R. Powell, B. E. Wolfe, R. M. Callaway, G. C. Thelen, S. Hallet, D. Prati and J. N. KliRonomos (2006): Invasive plants suppress the growth of native tree seedlings by disrupting below ground mutualisms. Plos Biology 4e140: 0727-1731.

TADEY, M., J. C. TADEY and N. TADEY (2009): Reproductive biology of five native plant species from the Monte Desert of Argentina. Botanical Journal of the Linnean Society 161: 190-201.
Tortosa, R. D., A. Bartoli, N. L. Gil-AD and N. BarTOLONI (2000): Analysis of hybridization between Grindelia brachystephana and G. chiloensis (Asteraceae: Astereae) in Patagonia, Argentina. Plant Systematics and Evolution 224: 243-253.

WALSH, R. A. (1993): Grindelia squarrosa. In: Fire Effects Information System, [Online]. USDA Forest Service, Rocky Mountain Research Station, Fire Sciences Laboratory (Producer) (http://www.fs.fed.us/database/feis/ plants/forb/grisqu/all.html) (accessed 2012, February 1).

\title{
Early Selection for Improving Volume Growth in Coastal Douglas-fir Breeding Programs
}

\author{
By T. Z. YE* ${ }^{*}$ and K. J. S. JAYAWICKRAMA \\ Department of Forest Ecosystems and Society, Oregon State University, \\ 321 Richardson Hall, Corvallis, OR 97331, USA
}

(Received $10^{\text {th }}$ February 2012)

\begin{abstract}
Measurements on growth traits up to 41 years of age from 68 progeny sites in eight first-generation breeding zones of coastal Douglas-fir (Pseudotsuga menziesii [Mirb.] Franco var. menziesii) in the US Pacific Northwest were used to investigate age trends of genetic parameters and to determine optimum age of selection. Heritabilities and age-age genetic correlations were estimated using univariate or bivariate mixed model analyses.

Heritability estimates tended to increase with age for both total growth and growth increment traits. The estimates showed different age trends among breeding zones, but the differences were generally small. Age-age genetic correlations for total growth traits fitted Lambeth's model surprisingly well, despite the data being collected from multiple breeding zones.

Using rotation-age (i.e., 50yr) volume as the selection criterion, the greatest correlated gains per year were achieved by making family selection at juvenile ages (i.e., 9 for height, 13 for diameter, and 11 for volume). Similar results were obtained for within-family selection except that the optimum ages of selection were 2 4 years later than that from family selection, i.e., 11 for height, 15 for diameter and volume. Early selection on total height was always more efficient and had earlier optimum ages than on other growth traits. The optimum ages of early family selection on total growth were 4 11 years earlier than on the corresponding growth increment traits. It was also evident that the optimum ages of selection occurred later for slow-growth trials than for fast-growing trials.
\end{abstract}

Key words: Douglas-fir, growth, growth increment, early selection, selection efficiency, optimum age, heritability, age-age genetic correlation.

*) Corresponding Author: TerRance Z. YE. Tel: (541) 737-9881, Fax: (541) 737-1393. E-Mail: Terrance.Ye@oregonstate.edu

\section{Introduction}

Forest trees often have long rotations and produce seed late, and therefore long generation intervals. Selection for growth traits in tree breeding programs usually takes place long before rotation age to shorten the breeding cycle and maximize genetic gain per unit time. The optimum age for selection and the choice of measurement traits are vitally important to the long-term efficiency of any tree breeding program (LAMBETH, 1980; ZOBEL and TALBERT, 1984).

The biologically optimum age for selection has been defined as the selection age when average annual gain towards the breeding objective is maximized (KANG, 1985). It can be determined using theory of quantitative genetics if the heritabilities of the juvenile and mature traits and their genetic correlation are known. While heritabilities and age-age correlations for growth have been reported for many coniferous species such as loblolly pine (e.g., McKeand, 1988; LAMBETH and Dill, 2001; GWAZE and BRIDGWATER, 2002), radiata pine (e.g., MATHESON et al., 1994), lodgepole pine (e.g., XIE and YING, 1996), slash pine (e.g., White and HodGe, 1992), Douglas-fir (e.g., JOHNSON et al., 1997; DEAN and StONECYPHER, 2006), Scots pine (e.g., JANSSON et al., 2003) and jack pine (e.g., WENG et al., 2007), these parameters at mature stages are seldom known, and are usually predicted using attributes measured in juvenile progeny trials.

Stem volume is usually the most important trait in determining tree value. Thus, genetic improvement in volume growth has been the highest priority in most tree improvement programs. Early selection for rotation-age stem volume is often conducted based on juvenile height growth (e.g., MCKEAND, 1988; DEAN and 
STONECYPHER, 2006) because height tends to have higher estimates of heritability (Foster, 1986; CoRnELIUS, 1994) and is less affected by competition (LAMBETH et al., 1983; Foster, 1986) than diameter. On the contrary, other studies showed that selection using juvenile diameter or stem volume as selection criterion could be more efficient than that based on juvenile height (e.g., KING et al., 1988; XIE and YING, 1996). Growth traits in trees are cumulative since successive annual growth increments add up to the total growth. Hence, growth increments at various ages might be important to the juvenile-mature correlations and affect the predictions of later performance. However, the genetic properties and relative efficiency of selection for growth increment have rarely been studied systematically in forest genetics and tree breeding.

Douglas-fir [Pseudotsuga menziesii (MIRB.) FRANCO] dominates the most productive forest lands of western North America (SILEN, 1978) and is the prime species for intensive forest management and tree improvement in the Pacific Northwest (KING et al., 1988). Large-scale operational breeding programs for coastal Douglas-fir started in the US Pacific Northwest in the mid 1960's. Since then, over 1,150 test plantations ( $1^{\text {st }}$ - and $2^{\text {nd }}$-generation) have been established by members of the Northwest Tree Improvement Cooperative (NWTIC) in coastal Oregon and Washington. Many studies have reported on the age-related trends of genetic parameters and the efficiency of early selection for growth traits of Douglas-fir (e.g., NAMKOONG et al., 1972; KING et al., 1988; MAGNUSSEN and YANCHUK, 1993; WoODS et al., 1995; StONECYPHER et al., 1996; JoHnson et al., 1997; DeAn and Stonecypher, 2006). Most of them estimated selection efficiencies and correlations based on comparisons between data from juvenile ages of the same progeny test or a small number of tests, which limited the reliability and representativeness of the results. The most comprehensive study was done by JoHNSON et al. (1997) which summarized the results on the growth data collected from 51 progeny tests across western Oregon. While this study provided valuable information on early selection, it reported only on growth data measured at ages $5 \sim 25$ (mostly $\leq 20 \mathrm{yr}$.) less than half the rotation age of commercial Douglas-fir plantations. Moreover, only height-height and diameter-diameter prediction models were evaluated in this study, and the models for predicting stem volume at maturity were not presented.

In this paper, we explored the genetic time trends and the efficiency of early selection of Douglas-fir on various traits and selection criterions using growth data of 266,010 trees up to age 41 from 68 open-pollinated progeny tests ( 8 breeding zones) across western Oregon. Measurement data collected at such a large range of measurement ages across such a wide range of environments allow for a more throughout study of the agerelated genetic patterns. The objectives of this study were to (1) determine the optimum ages of selection and best selection criterion for both family and within-family selections to maximize per-year gain in stem volume at rotation age; (2) evaluate the relative efficiency of selection based on total growth (i.e., height, diameter, and volume) and the related growth increments at various ages; (3) investigate if the optimum age of selection is related to the test plantation's early growth rate; and (4) evaluate implications of these results for decisions on early selection in Douglas-fir.

\section{Materials and Methods}

Test materials, experimental designs and measurements

Sixty-eight open-pollinated progeny trials of Douglasfir from eight first-generation breeding zones were established from 1970 to 1984 across western Oregon (Table 1), as part of the first-generation testing series conducted by the Industrial Forestry Association - Progressive Tree Improvement system (SILEN and WHEAT, 1979), precursor to the NWTIC. All parents were selected from natural stands within breeding zones at very low selection intensity. As a results, a large number of open-pollinated families (366 on average) were tested on $4 \sim 15$ sites (9 on average) in each breeding zone. The geographic locations of these field trials varied in latitude $\left(42.0 \sim 48.1^{\circ} \mathrm{N}\right)$, longitude $\left(121.39 \sim 124.5^{\circ} \mathrm{W}\right)$ and elevation $(43 \sim 1,220 \mathrm{~m})$.

The open-pollinated families were assigned to sets of 25 to 50 families. Each family was usually represented by $30 \sim 70$ individuals across sites. All the trials were established in either a "reps-in-sets" or a "sets-in-reps" design. In a "reps-in-sets" design, all replicates of a single set of families were planted together. This can be viewed as planting a number of separate mini progeny trials at each location (JOHNSON et al., 1997). In a "setsin-reps" design, however, each replicate included all the sets of families (SchuTz and CocKerHAM, 1966). Singletree plots were used in all trials; with tree spacing varying from $2.4 \times 2.4$ to $3.5 \times 3.5$ meters. Mechanical thinning was conducted once or twice when the trials passed age 25. At least 100 families remained per site after thinning and families were represented by at least $15 \sim 25$ offspring, which should still be sufficient for providing reasonably accurate progeny testing and reliable estimation of genetic parameters (ROBERTSON, 1957; CotTERILL and JAMES, 1984; WHITE, 1996).

Total tree height (HT) and diameter at breast height (DBH) were usually measured in all sets/replicates in the early measurements, while only a subset of sets/replicates were measured at later ages to reduce the measurement costs. The final measurement ages from seed in these trials varied between 20 to 41 years from seed. Stem volume index (VOL) was calculated approximately as whenever both HT and DBH measurements were available. We avoided the use of volume equations developed based on a standard diameter reference height measure (e.g., BRUCE and DEMARS, 1974; SMith and DeMAERSCHALK, 1974) because they become inaccurate or inapplicable for small trees, and due to evidence that genetic parameters and rankings from such volume equations are essentially the same as from $H T \times D B H^{2}$.

Mean annual growth increments for height $\left(H T \_I N C\right)$, diameter (DBH_INC), and volume $\left(V O L \_I N C\right)$ were obtained for the intervals between successive measure- 
Table 1. - Details on traits and assessment ages for the 8 first-generation Douglas-fir breeding zones in western Oregon. HT, DBH, and VOL are overall height, diameter at breast height, and volume index, respectively; and HT_INC, DBH_INC, and VOL_INC are the corresponding increments, respectively.

\begin{tabular}{|c|c|c|c|c|c|c|c|c|c|}
\hline \multirow{2}{*}{ Program } & \multirow{2}{*}{$\begin{array}{c}\# \\
\text { sites }\end{array}$} & \multirow{2}{*}{ \# trees } & \multirow{2}{*}{$\begin{array}{c}\# \\
\text { families }\end{array}$} & \multicolumn{6}{|c|}{ Assessment ages } \\
\hline & & & & HT & DBH & HT_INC & DBH_INC & VOL & VOL_INC \\
\hline BLM Lorane & 6 & 27,426 & 220 & $3,5,10,15$ & $10,15,20$ & $\begin{array}{l}3 \sim 5,5 \sim 10 \\
10 \sim 15\end{array}$ & $10 \sim 15,15 \sim 20$ & 10,15 & $10^{\sim} 15$ \\
\hline BLM McKenzie & 15 & 51,743 & 592 & $3,5,10,15$ & $10,15,20$ & $\begin{array}{l}3 \sim 5,5^{\sim 10} \\
10 \sim 15\end{array}$ & 10 15, 15 20 & 10,15 & $10 \sim 15$ \\
\hline Burnt Woods 1 & 8 & 10,242 & 161 & $\begin{array}{l}8,10,15 \\
20 / 24 \\
36 / 38 / 41\end{array}$ & $\begin{array}{l}8,15 \\
20 / 24 \\
36 / 38 / 41\end{array}$ & $\begin{array}{l}8^{\sim} 10,10 \sim 15, \\
15 \sim 20,20 \sim 41\end{array}$ & $\begin{array}{l}8 \sim 15,15 \sim 20, \\
20 \sim 41\end{array}$ & $\begin{array}{l}8,15 \\
20 / 24 \\
36 / 38 / 41\end{array}$ & $\begin{array}{l}8 \sim 15,15 \sim 20, \\
20 \sim 41\end{array}$ \\
\hline Burnt Woods 2 & 7 & 32,600 & 329 & $\begin{array}{l}5,9,15,22 \\
24 / 28\end{array}$ & $\begin{array}{l}15,22 \\
24 / 28\end{array}$ & $\begin{array}{l}5 \sim 9,9 \sim 15 \\
15 \sim 24 / 28\end{array}$ & $\begin{array}{l}15^{\sim 22} \\
22 \sim 24 / 28\end{array}$ & $15,24 / 28$ & $15^{\sim} 24 / 28$ \\
\hline Sunday Creek & 4 & 14,096 & 120 & $5,10,15,24$ & 15,24 & $\begin{array}{l}5^{\sim 10}, 10 \sim 15, \\
15^{\sim} 24\end{array}$ & $15 \sim 24$ & 15,24 & $15 \sim 24$ \\
\hline Umpqua Noti & 9 & 29,217 & 326 & $5,10,15$ & $\begin{array}{l}5,10,15 \\
30\end{array}$ & $5 \sim 10,10 \sim 15$ & $\begin{array}{l}5 \sim 10,10 \sim 15, \\
15 \sim 30\end{array}$ & $5,10,15$ & $10 \sim 15$ \\
\hline $\begin{array}{l}\text { Umpqua } \\
\text { Swisshome }\end{array}$ & 7 & 21,772 & 270 & $5,10,15$ & $10,15,30$ & $5 \sim 10,10 \sim 15$ & $10 \sim 15,15 \sim 30$ & 10,15 & $10 \sim 15$ \\
\hline Vernonia & 12 & 78,914 & 909 & $\begin{array}{l}7 / 9,10 / 12 \\
15,20,25,30\end{array}$ & $\begin{array}{l}7 / 9,12, \\
15,20,25, \\
30\end{array}$ & $\begin{array}{l}7 \sim 10, \\
10 / 12 \sim 15, \\
15^{\sim} 20, \\
20^{\sim} 25,25 \sim 30\end{array}$ & $\begin{array}{l}\text { 7 12, 12 15, } \\
15^{\sim} 20, \\
20 \sim 25,25 \sim 30\end{array}$ & $\begin{array}{l}7 / 9,12,15 \\
20,25,30\end{array}$ & $\begin{array}{l}7 \sim 12,12 \sim 15, \\
15 \sim 20, \\
20 \sim 25,25 \sim 30\end{array}$ \\
\hline TOTAL & 68 & 266,010 & 2927 & & & & & & \\
\hline
\end{tabular}

ments and converted to annual basis, assuming equal annual increments between measurements. For example, age-15 HT_INC was calculated as $\left(H T_{15}-H T_{10}\right) / 5$, where the subscripts indicate tree ages from seed.

\section{Univariate analyses}

For each trait, a univariate family model was used for estimating variance components and heritabilities within each breeding zone. The following linear model was fitted using ASReml software (GILMOUR et al., 2009):

$$
y_{i j k l m}=\mu+S_{i}+\alpha_{j}+(S \alpha)_{i j}+R_{k(i)}+F_{l}+(S F)_{i l}+\varepsilon_{i j k l m}
$$

where $y_{i j k l m}=$ observation of the $m$ th tree in the $l$ th family in the $k$ th replicate in the $j$ th set and $i$ th site, $\mu$ =population mean, $S_{i}=$ fixed effect of $i$ th site, $\alpha_{j}=$ fixed effect of the $j$ th set, $(S \alpha)_{i j}=$ fixed interaction between $i$ th site and $j$ th set, $R_{k(i)}=$ random effect of $k$ th replicate within $i$ th site, $F_{l}=$ random effect of $l$ th family, $(S F)_{i l}=$ random interaction between $i$ th site and $l$ th family, and $\varepsilon_{i j k l m}=$ random residual. Replicate was coded within set and site for "reps-in-sets" design and coded within site for "sets-in-reps" design, so that model (1) fits both experimental designs. Prior to conducting a pooled across-site analysis, data was standardized by dividing each observation by the phenotypic standard deviation derived from that site, with the purposes to homogenize variances across sites and to eliminate statistically significant genotype $\times$ environment interactions caused by scale effects.

Individual-tree heritability $\left(h^{2}{ }_{i}\right)$ was estimated as the ratio of additive genetic variance $\left(V_{A}\right)$ over the total phenotypic variance $\left(V_{P}\right)$ among individual trees across sites within a breeding zone:

$$
h_{i}^{2}=\frac{V_{A}}{V_{P}}=\frac{4 \cdot \sigma_{f}^{2}}{\sigma_{f}^{2}+\sigma_{s f}^{2}+\sigma_{e}^{2}}
$$

where $\sigma_{f}^{2}, \sigma_{s f}^{2}$, and $\sigma_{e}^{2}$ are the estimated variance components of family, site $\times$ family, and residual effects, respectively. Similarly, within-family heritability $\left(h^{2}{ }_{w}\right)$ was calculated as (Namkoong, 1979):

$$
h_{w}^{2}=\frac{3 \cdot \sigma_{f}^{2}}{\sigma_{s f}^{2}+\sigma_{e}^{2}}=\frac{(3 / 4) \cdot h_{i}^{2}}{1-h_{i}^{2} / 4}
$$

Family mean heritability $\left(h_{f}^{2}\right)$ was calculated from individual-tree heritability by assuming 30 offspring per family $(n)$ using the following equation (BAKER, 1986; FALCONER and MACKAY, 1996):

$$
h_{f}^{2}=h_{i}^{2} \cdot \frac{1+(n-1) / 4}{1+(n-1) \cdot h_{i}^{2} / 4}
$$

Heritabilities were also estimated for the subset of data where one-third of the slowest growing sites (i.e., the poorest average age- 10 height growth) were excluded from each breeding zone, with the purpose of investigating the effect of the early growth of the plantation on heritability estimates.

\section{Bivariate analyses}

Bivariate analyses were carried out to estimate genetic correlations between traits and ages using a bivariate mixed family model, expressed in matrix format:

$$
\mathbf{y}=\mathbf{X}_{1} \mathbf{s}+\mathbf{X}_{2} \boldsymbol{\alpha}+\mathbf{X}_{3} \boldsymbol{\beta}+\mathbf{Z}_{1} \mathbf{r}+\mathbf{Z}_{2} \mathbf{f}+\mathbf{Z}_{3} \boldsymbol{\delta}+\mathbf{e}
$$

where $\mathbf{y}=\left[\mathbf{y}_{1}^{\prime}, \mathbf{y}_{2}^{\prime}\right], \mathbf{y}_{1}$ and $\mathbf{y}_{2}$ are the vectors of individual tree observations for two ages; $\mathbf{s}=\left[\mathbf{s}_{1}^{\prime}, \mathbf{s}_{2}{ }_{2}\right], \mathbf{s}_{1}$ and $\mathbf{s}_{2}$ 
are the vectors of fixed site effects; $\alpha=\left[\alpha_{1}^{\prime}, \alpha_{2}^{\prime}\right], \alpha_{1}$ and $\boldsymbol{\alpha}_{\mathbf{2}}$ are the vectors of fixed set effects; $\boldsymbol{\beta}=\left[\boldsymbol{\beta}_{1}, \boldsymbol{\beta}_{\mathbf{2}}\right], \boldsymbol{\beta}_{1}$ and $\boldsymbol{\beta}_{2}$ are the vectors of fixed site $\times$ set interaction effects; $\mathbf{r}=\left[\mathbf{r}_{1}^{\prime}, \mathbf{r}_{2}^{\prime}\right], \mathbf{r}_{1}$ and $\mathbf{r}_{2}$ are the vectors of random replicate effects: $\mathbf{f}=\left[\mathbf{f}_{1}, \mathbf{f}_{\mathbf{2}}\right], \mathbf{f}_{\mathbf{1}}$ and $\mathbf{f}_{\mathbf{2}}$ are the vectors of random family effects; $\boldsymbol{\delta}=\left[\boldsymbol{\delta}_{1}^{\prime}, \boldsymbol{\delta}_{2}^{\prime}\right], \boldsymbol{\delta}_{1}$ and $\boldsymbol{\delta}_{2}$ are the vectors of random site $\times$ family interaction effects; $\mathbf{e}=\left[\mathbf{e}_{1}^{\prime}, \mathbf{e}_{2}^{\prime}\right], \mathbf{e}_{1}$ and $\mathbf{e}_{2}$ are the vectors of random residuals; $\mathbf{X}_{1}, \mathbf{X}_{2}, \mathbf{X}_{3}, \mathbf{Z}_{1}, \mathbf{Z}_{2}, \mathbf{Z}_{3}$ are incidence matrices connecting the observations to site, set, site $\times$ set, replicate, family, and site $\times$ family effect, respectively.

Variances and covariances were estimated using ASReml software. Genetic correlations $\left(r_{g}\right)$ were also calculated within ASReml according to the standard formulae (FALCONER and MACKAY, 1996).

As in the univariate case, we calculated genetic correlations using bivariate analyses and the subset of data where one-third of test sites with poorest age-10 average height growth were excluded from each breeding zone.

\section{Trends in heritabilities and age-age genetic correlations}

The age trends in heritabilities (i.e., $h_{i}^{2}, h_{f}^{2}$, and $h_{w}^{2}$ ) were assessed across breeding zones and modeled using the following linear and non-linear equations. These forms of relationship were commonly reported in literature such as JoHnson et al. (1997), GREAVES et al. (2003), and Bouvet et al. (2007).

$$
\begin{aligned}
& h^{2}=a+b \cdot a g e \\
& h^{2}=a+b \cdot \ln (\text { age }) \\
& h^{2}=a+b \cdot a g e+c \cdot a g e^{2}
\end{aligned}
$$

where age is the selection age in years; $a, b$, and $c$ are coefficients.

The model developed by LAMBETH (1980) was used to fit age-age genetic correlations:

$$
r_{g_{\text {age } 1, a g e 2}}=a+b \cdot L A R
$$

where $L A R=\ln ($ age 1 /age 2$)$, i.e., natural logarithm of the age ratio for the two ages at which data were obtained (younger age/older age). In addition, the following four non-linear models were also tested:

$$
\begin{aligned}
& r_{g_{\text {age l,age } 2}}=a+b \cdot L A R^{2} \\
& r_{g_{\text {agel ,age } 2}}=a+b \cdot L A R^{3} \\
& \ln \left(r_{g_{\text {agel ,age } 2}}\right)=a+b \cdot L A R^{s} \\
& r_{g_{\text {agel ,age } 2}}=a+b \cdot L A R+c \cdot L A R^{2}
\end{aligned}
$$

For both heritabilities and genetic correlation, best models were chosen based on degree of freedom adjusted $\mathrm{R}$-square and statistical significance of model and coefficients. Heritability and genetic correlation estimates were then interpolated for ages at which no assessments were taken. We also extrapolated the estimates of genetic parameters from age of 41 to a rotation age of 50 using the fitted models.

\section{Efficiency of early selection}

Efficiency of early selection was examined using rotation-age (i.e., 50yr) volume as the target trait. Assuming equal intensities of selection at both selection and rotation ages, efficiency of early selection per breeding cycle $(E)$ is given by (FALCONER and MACKAY, 1996):

$$
E=r_{g} \cdot h_{J} / h_{M}
$$

where $r_{g}$ is age-age genetic correlation; $h_{J}$ and $h_{M}$ are square roots of heritability $\left(h^{2}\right.$ for mass selection, $h^{2}{ }_{f}$ for family selection, and $h^{2}{ }_{w}$ for within-family selection) at selection and rotation ages, respectively.

By selecting trees at an early age, tree breeders usually hope to increase the genetic gain per unit time instead of per breeding cycle (DICKERSON and HAZEL, 1944; KANG, 1985). Efficiency of early selection in terms of gain per year $(Q)$ was calculated as follows (FALCONER and MACKAY, 1996):

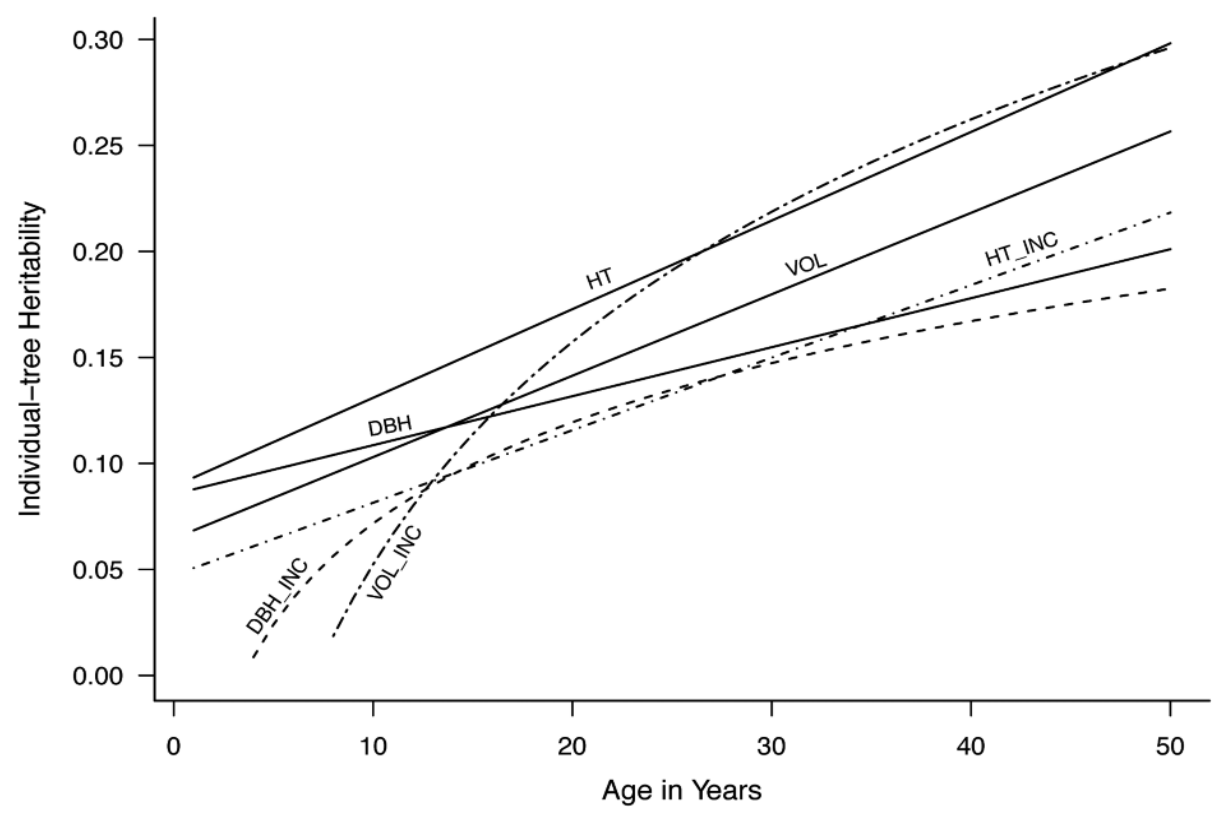

Figure 1. - Predicted age-trends of individual-tree heritability estimates. 


$$
Q=E \cdot \frac{T_{M}+t}{T_{J}+t}
$$

where $T_{J}$ and $T_{M}$ are selection and rotation ages, respectively; $t$ is the delay between selection and production of sufficient propagules to allow establishment of the next cycle of genetic tests (we assumed $t=7$ for Douglas-fir in the Pacific Northwest).

There are economic benefits in realizing gain sooner rather than later. To determine the economic optimum, we calculated the discounted efficiency of early selection $\left(Q^{\prime}\right)$ as described by White and Hodge (White and HoDGE, 1992):

$$
Q^{\prime}=E \cdot \frac{(1+d)^{T_{M}}}{(1+d)^{T_{J}}}
$$

where $d$ is the interest rate.

\section{Results}

\section{Age trends in heritabilities}

For total growth traits (i.e., HT, DBH, and VOL), there were linear increasing trends in heritability estimates with age (Figure 1). For example, the average individual-tree heritabilities increased from 0.13 (HT) and $0.11(\mathrm{DBH})$ at age 10 to $0.25(\mathrm{HT})$ and $0.18(\mathrm{DBH})$ at age 40. HT demonstrated higher heritability estimates than $\mathrm{DBH}$ and VOL at all ages investigated. These trends were well described by simple linear models (Table 2). DBH had a relatively smaller slope than HT and VOL.

Table 2. - Fitted age trends of individual-tree heritability.

\begin{tabular}{llll}
\hline Trait & Best Equation & $\mathrm{R}^{2}$ & $\mathrm{Pr}>\mathrm{F}$ \\
\hline HT & $h^{2}=0.08915+0.00418 \cdot$ age & 0.515 & 0.004 \\
DBH & $h^{2}=0.08548+0.00231 \cdot$ age & 0.221 & 0.059 \\
VOL & $h^{2}=0.06456+0.00384 \cdot$ age & 0.506 & 0.006 \\
HT_INC & $h^{2}=0.04722+0.00342 \cdot$ age & 0.163 & 0.194 \\
DBH_INC & $h^{2}=-0.08677+0.06882 \cdot \ln ($ age $)$ & 0.473 & 0.013 \\
VOL_INC & $h^{2}=-0.29629+0.15142 \cdot \ln ($ age $)$ & 0.622 & 0.011 \\
\hline
\end{tabular}

While the age trend in heritability for HT increment was best fitted using linear regression, fitting a non-linear relationship was slightly better than a linear relationship for the trends between heritability and age for DBH and VOL increments (Table 2). As shown in Figure 1, heritabilities for DBH_INC and VOL_INC increased with age more quickly at the juvenile stage (to age-15 or so) than at later stages.

Significant but small differences in intercept and slope were found for each trait between the two breeding zones (i.e., Vernonia and Burnt Woods 1) where enough degrees of freedom were provided (data not shown).

For both HT and DBH, total growth consistently showed higher heritabilities than growth increments at all ages. Heritability for VOL_INC, however, began at a very low level (only 0.05 at age 10 , Figure 1 ) but rose to 0.13 at age 17, reaching the same level as VOL. After age 17, VOL_INC had higher heritabilities than VOL.

All fitted models except for HT_INC were statistically significant or marginally significant (Table 2).

\section{Age-age genetic correlations}

Data from all breeding zones were combined and used to construct regression equations with age-age genetic correlation as the dependent variable on $L A R$ in order to have enough degrees of freedom for regression analyses as well as old-age measurements. The best fitted equations are shown in Table 3.

The juvenile-mature genetic correlations for total growth (i.e., HT, DBH, VOL) were fitted well with the equation developed by LAMBETH $(1980 ; r=a+b \cdot L A R)$, with $R^{2}=0.78 \sim 0.92$. Using $L A R^{2}$ instead of $L A R$ did not result in any improvement in model fit. For all increment traits, however, we found that a simple non-linear model (i.e., $\ln (r)=a+b \cdot L A R^{3}$ ) gave a better fit than the simple linear model using $L A R$, with $R^{2}=0.61 \sim 0.81$. The genetic correlations between early height or diameter growth and age-50 stem volume (VOL50) were also strong, and well fitted with Lambeth's equation using $L A R^{2}\left(R^{2}=0.63\right.$ for HT) or $L A R\left(R^{2}=0.94\right.$ for $\left.\mathrm{DBH}\right)$. With a simple non-linear or polynomial model, genetic

Table 3. - Fitted age-age genetic correlation.

\begin{tabular}{lllll}
\hline Trait $(J)$ & Trait $(\mathrm{M})$ & Best Equation & $\mathrm{R}^{2}$ & $\mathrm{Pr}>\mathrm{F}$ \\
\hline $\mathrm{HT}$ & $\mathrm{HT50}$ & $r_{g}=1.07069+0.29197 \cdot \mathrm{LAR}$ & 0.814 & 0 \\
DBH & $\mathrm{DBH} 50$ & $r_{g}=1.03640+0.24676 \cdot \mathrm{LAR}$ & 0.781 & 0 \\
VOL & VOL50 & $r_{g}=1.04451+0.29917 \cdot L A R$ & 0.917 & 0 \\
HT_INC & HT50 & $\ln \left(r_{g}\right)=-0.04922+0.13467 \cdot L A R^{3}$ & 0.663 & 0.001 \\
DBH_INC & DBH50 & $\ln \left(r_{g}\right)=-0.06923+0.40057 \cdot L A R^{3}$ & 0.608 & 0.005 \\
VOL_INC & VOL50 & $\ln \left(r_{g}\right)=-0.04306+0.27763 \cdot L A R^{3}$ & 0.811 & 0.006 \\
\hline HT & VOL50 & $r_{g}=0.83259-0.07438 \cdot L A R^{2}$ & 0.629 & 0 \\
DBH & VOL50 & $r_{g}=1.03318+0.33163 \cdot L A R$ & 0.940 & 0 \\
HT_INC & VOL50 & $r_{g}=0.66517-0.35669 \cdot L A R-0.28474 \cdot L A R^{2}$ & 0.313 & 0.222 \\
DBH_INC & VOL50 & $\ln \left(r_{g}\right)=-0.07039+0.15147 \cdot L A R^{3}$ & 0.534 & 0.161 \\
\hline
\end{tabular}

Note: $L A R=\ln \left(T_{J} / T_{M}\right)$ where $T_{j}$ and $T_{M}$ are selection age and rotation $(=50)$, respectively. 
correlation between early HT_INC or DBH_INC and VOL50 can be reasonably fitted $\left(R^{2}=0.31 \sim 0.53\right)$. All models were statistically significant $(\mathrm{P}<0.01)$ except for HT_INC and DBH_INC vs. VOL50.

The predicted correlations between growth traits measured at early ages and mature volume (VOL50) are illustrated in Figure 2. The juvenile-mature genetic cor- relations varied widely but showed, as expected, a general tendency of increasing with age (except for HT_INC after age 27 ). At young ages ( $\leq 22$ years), HT was genetically better correlated with VOL50 than DBH (or VOL) with VOL50, but the reverse was true beyond age 25 . Total growth traits were more genetically correlated with VOL50 than their corresponding increment traits

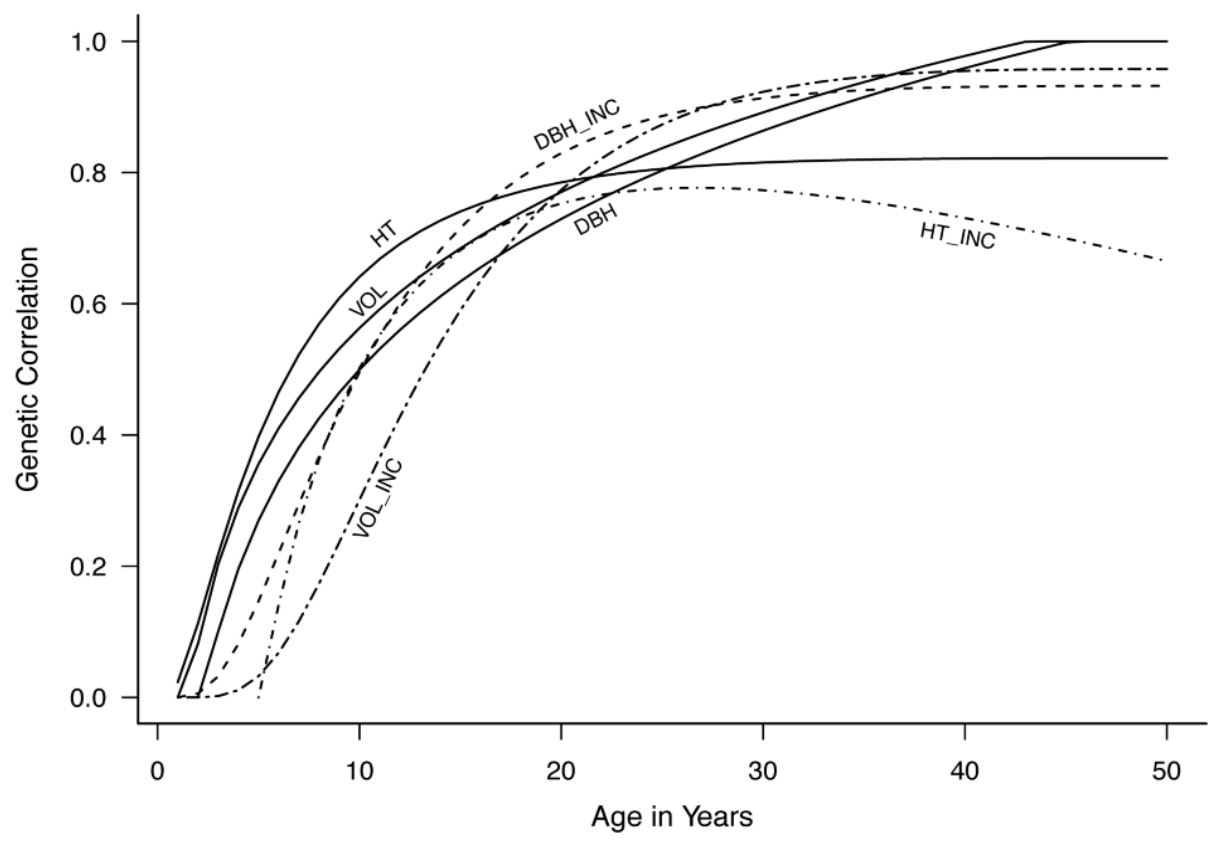

Figure 2. - Predicted age-age genetic correlations between growth traits and bole volume at age 50 .
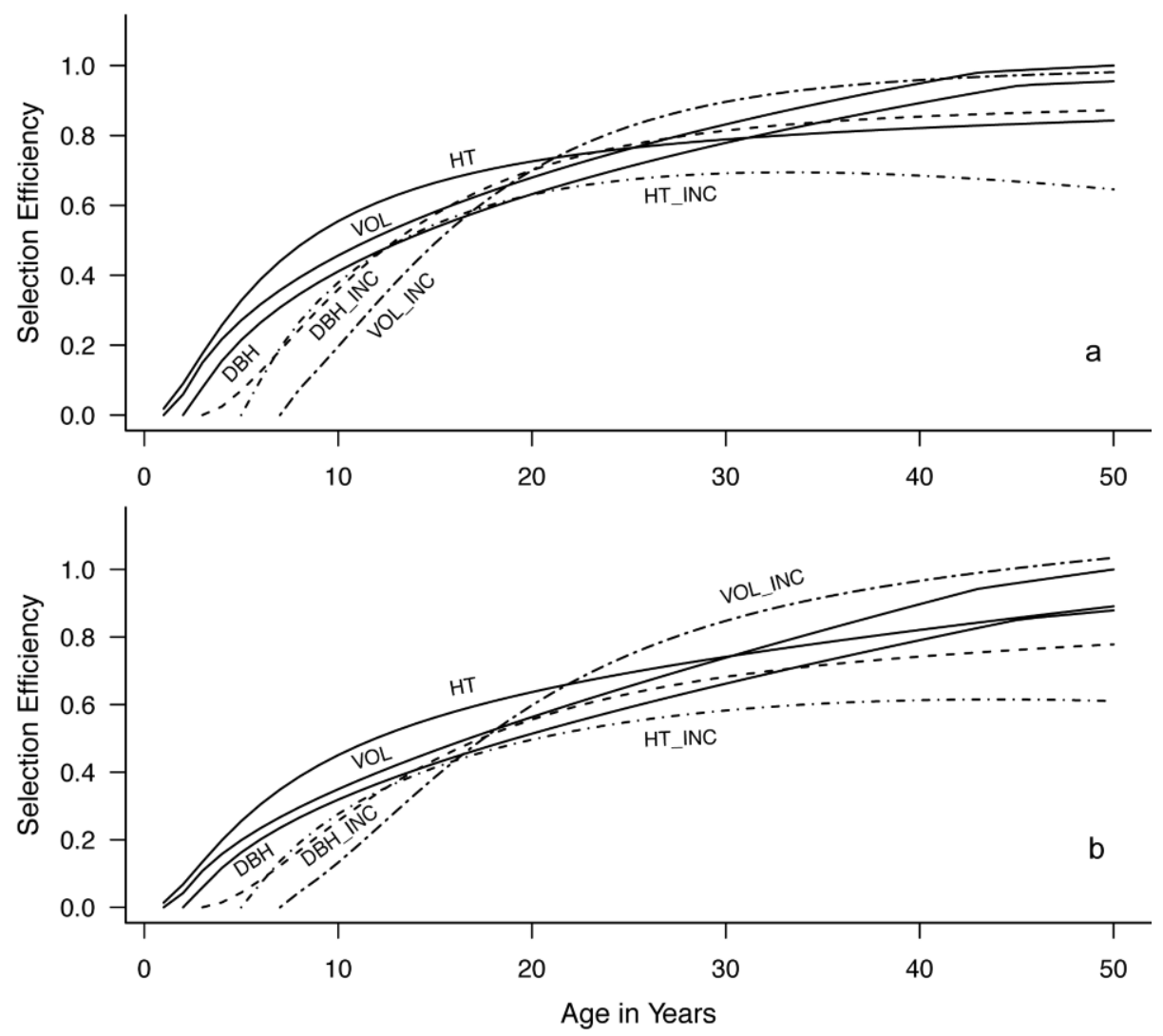

Figure 3. - Efficiencies of early selection using gain per generation $(E)$ relative to direct selection on age-50 volume; $a$-family selection, $b$-within-family selection. 

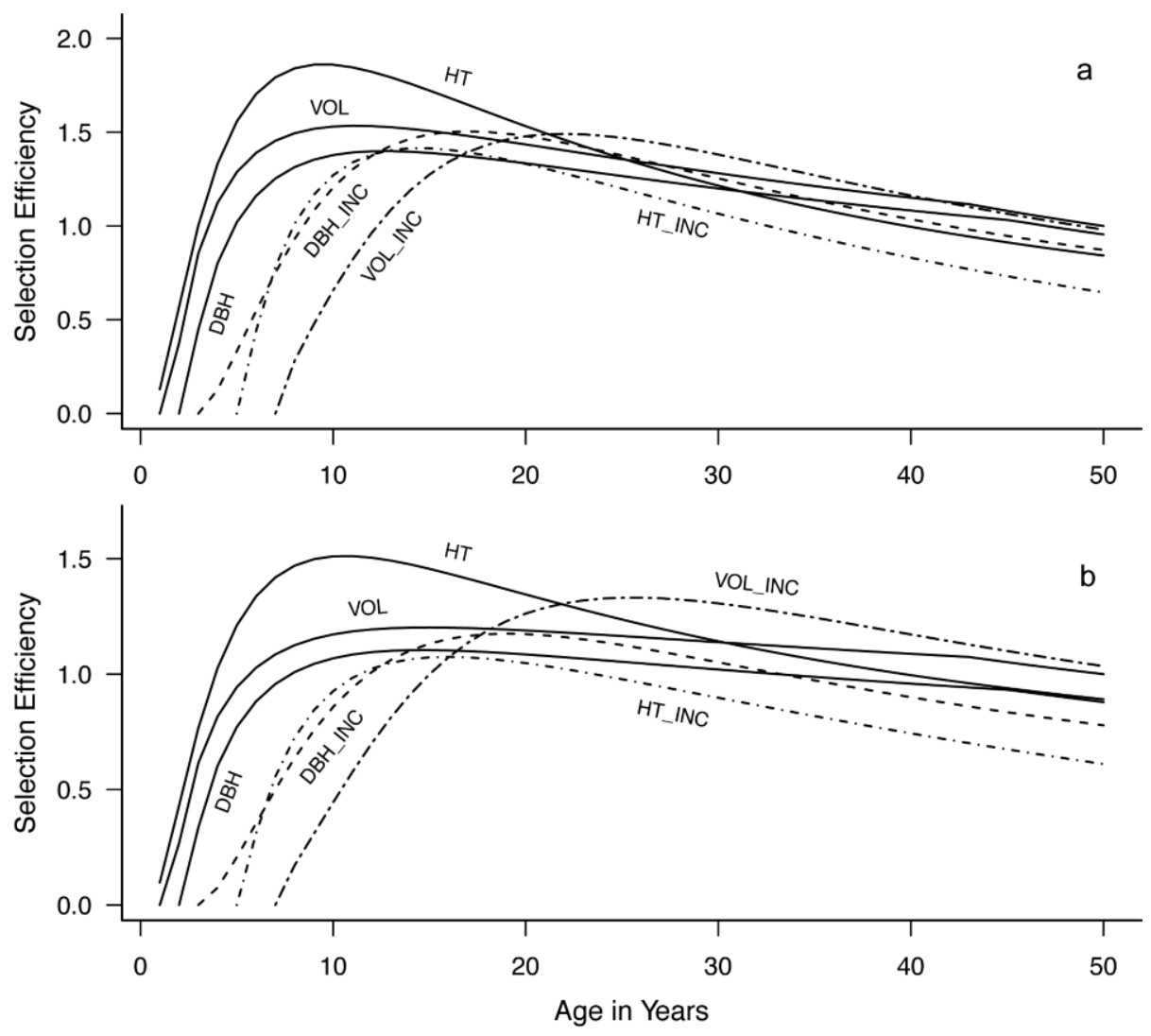

Figure 4. - Efficiencies of early selection using gain per year $(Q)$ relative to direct selection on age-50 volume; $\mathrm{a}$-family selection, $\mathrm{b}$ - within-family selection.

Table 4. - Summary of optimum ages of selection based on gain per year (Q) and discounted gain $\left(\mathrm{Q}^{\prime}\right.$, assuming interest rate $\left.d=6 \%\right)$.

\begin{tabular}{cccccc}
\hline \multirow{2}{*}{ Trait (J) } & \multirow{2}{*}{ Trait (M) } & \multicolumn{2}{c}{ Family selection } & \multicolumn{2}{c}{ Within-family selection } \\
\cline { 3 - 6 } & & Based on $Q$ & Based on $Q^{\prime}$ & Based on $Q$ & Based on $Q^{\prime}$ \\
\hline HT & 9 & 10 & 11 & 10 \\
DBH & 13 & 12 & 15 & 12 \\
VOL & \multirow{2}{*}{ VOL50 } & 11 & 11 & 15 & 12 \\
HT_INC & & 14 & 13 & 16 & 14 \\
DBH_INC & 17 & 15 & 19 & 16 \\
VOL_INC & & 22 & 18 & 26 & 20 \\
\hline HT & \multirow{2}{*}{ HT50 } & 10 & 10 & 12 & 11 \\
HT_INC & & 16 & 14 & 18 & 15 \\
\hline DBH & \multirow{2}{*}{ DBH50 } & 7 & 8 & 8 & 9 \\
DBH_INC & & 24 & 20 & 26 & 21 \\
\hline
\end{tabular}

Note: $L A R=\ln \left(T_{J} / T_{M}\right)$ where $T_{i}$ and $T_{M}$ are selection age and rotation (=50), respectively.

with VOL50 at very young ages ( $<11$ years). After age $12 \sim 20$, however, DBH_INC (or VOL_INC) exhibited stronger correlations with VOL50 than DBH (or VOL). By contrast, HT_INC had consistently lower genetic correlations with VOL50 than HT with VOL50 at all ages investigated.

\section{Efficiencies for early selection and optimum selection ages}

On gain per breeding cycle basis, efficiency $(E)$ for selecting VOL50 by early selection on various growth traits increased with age, regardless whether selection was conducted among or within families (Figure 3 ). Among all the traits studied, early selection on HT before age 22 yielded the highest genetic gain in VOL50. For example, the efficiencies of family selection on $\mathrm{HT}$, DBH, VOL, HT_INC, DBH_INC, and VOL_INC at age 10 were $55 \%, 41 \%, 46 \%, 38 \%, 36 \%$, and $20 \%$ relative to the gains from direct selection on VOL50, respectively. The efficiencies of within-family selection were slightly lower but showed the similar pattern as in family selection. After age 22, selection on VOL_INC became more 
effective. Results also indicated that selection on increment traits for VOL50 was generally inefficient at young ages ( $<13$ years). Between $14 \sim 35$ years, efficiency of selection on DBH_INC became slightly higher than on DBH. Using HT_INC was always less effective than using HT across all ages.
As shown in Figure $4 a$ and Table 4, genetic gains per year for improving VOL50 were maximized at ages 9 $(Q=1.86), \quad 13 \quad(Q=1.40)$, and $11 \quad(Q=1.53)$ when selecting on $\mathrm{HT}, \mathrm{DBH}$, and VOL through family selection, respectively. For increment traits, per year gains in VOL50 reached the maxima at ages 14
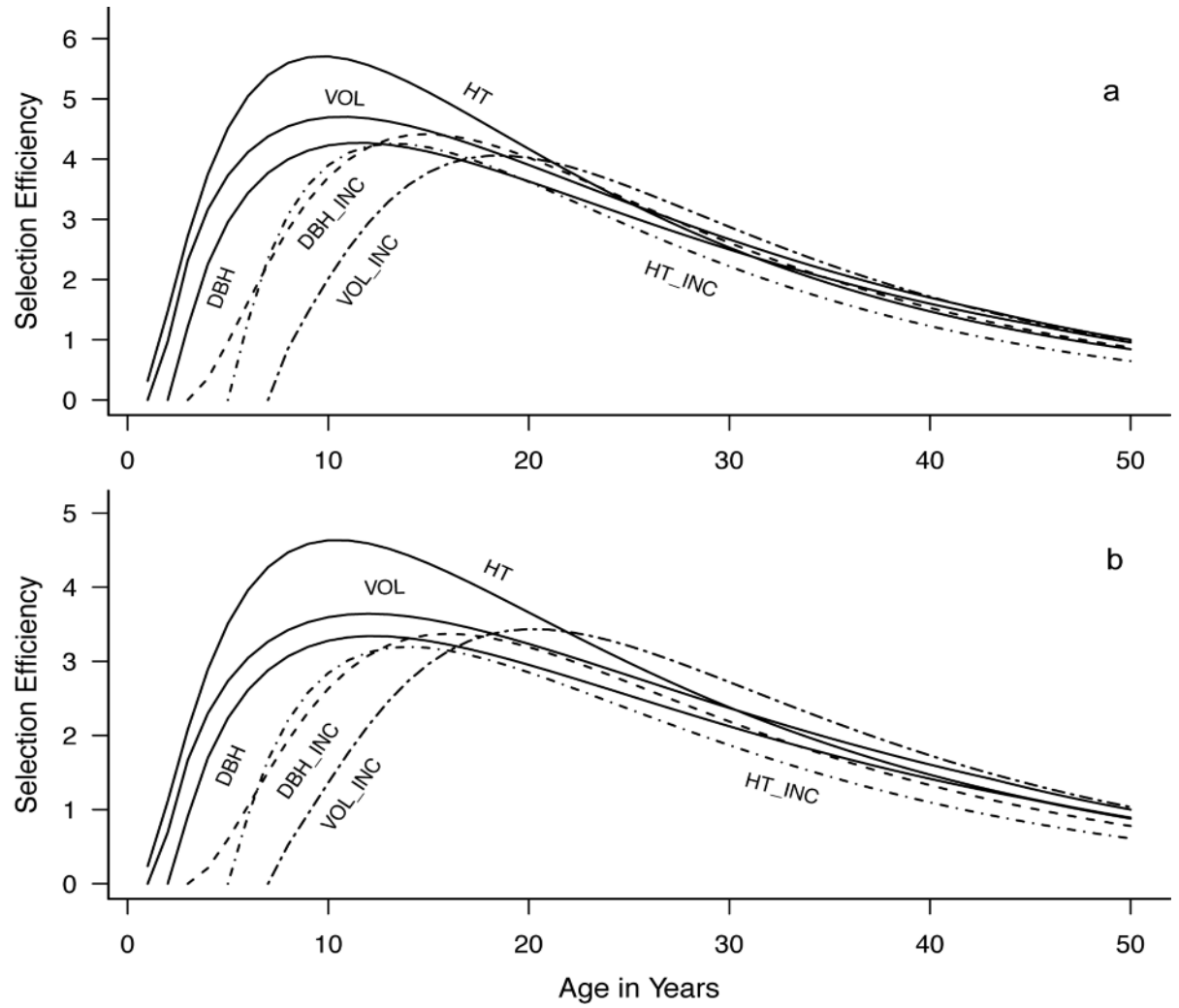

Figure 5. - Efficiencies of early selection using discounted gain $\left(Q^{\prime}\right)$ at interest rate of $6 \%$ relative to direct selection on age-50 volume; $a$-family selection, $b$-within-family selection.

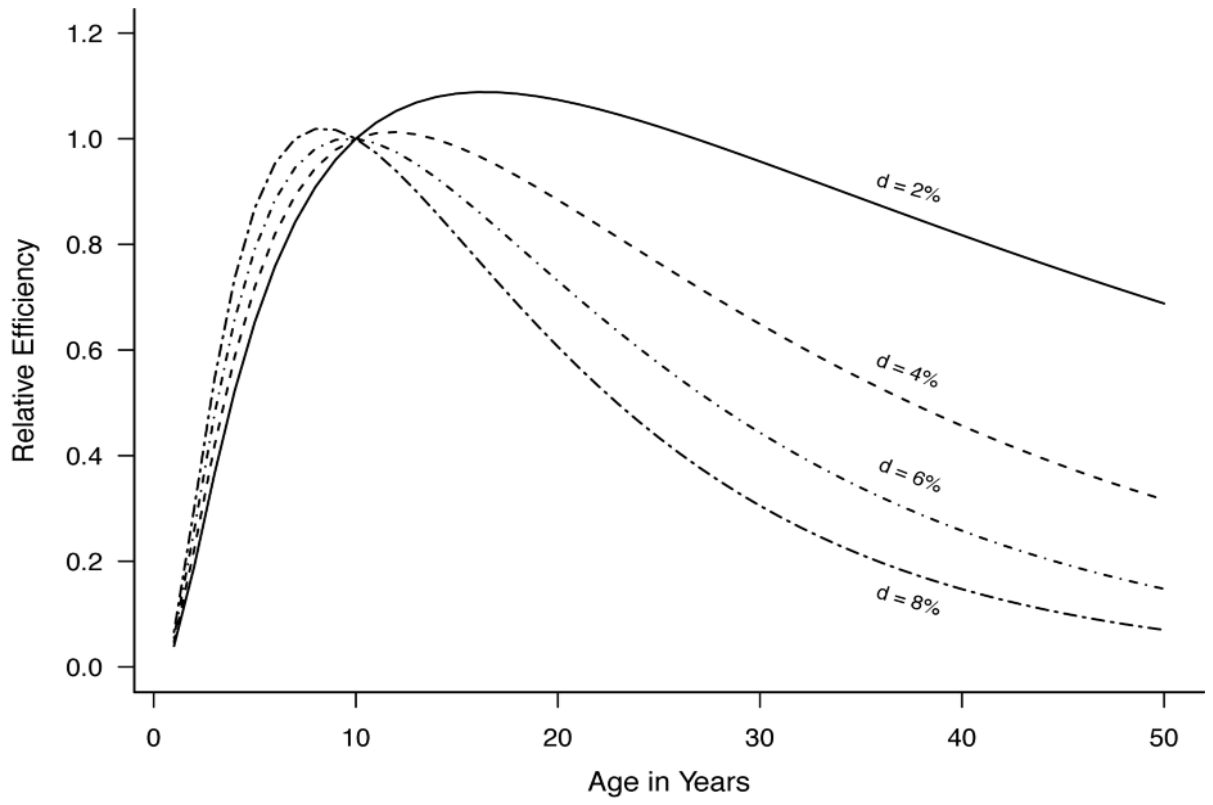

Figure 6. - Effect of interest rate $(d)$ on efficiency of family selection on height using discounted gain $\left(Q^{\prime}\right)$ relative to direct selection on age-50 volume (standardized to age-10 efficiency $=100 \%)$. 

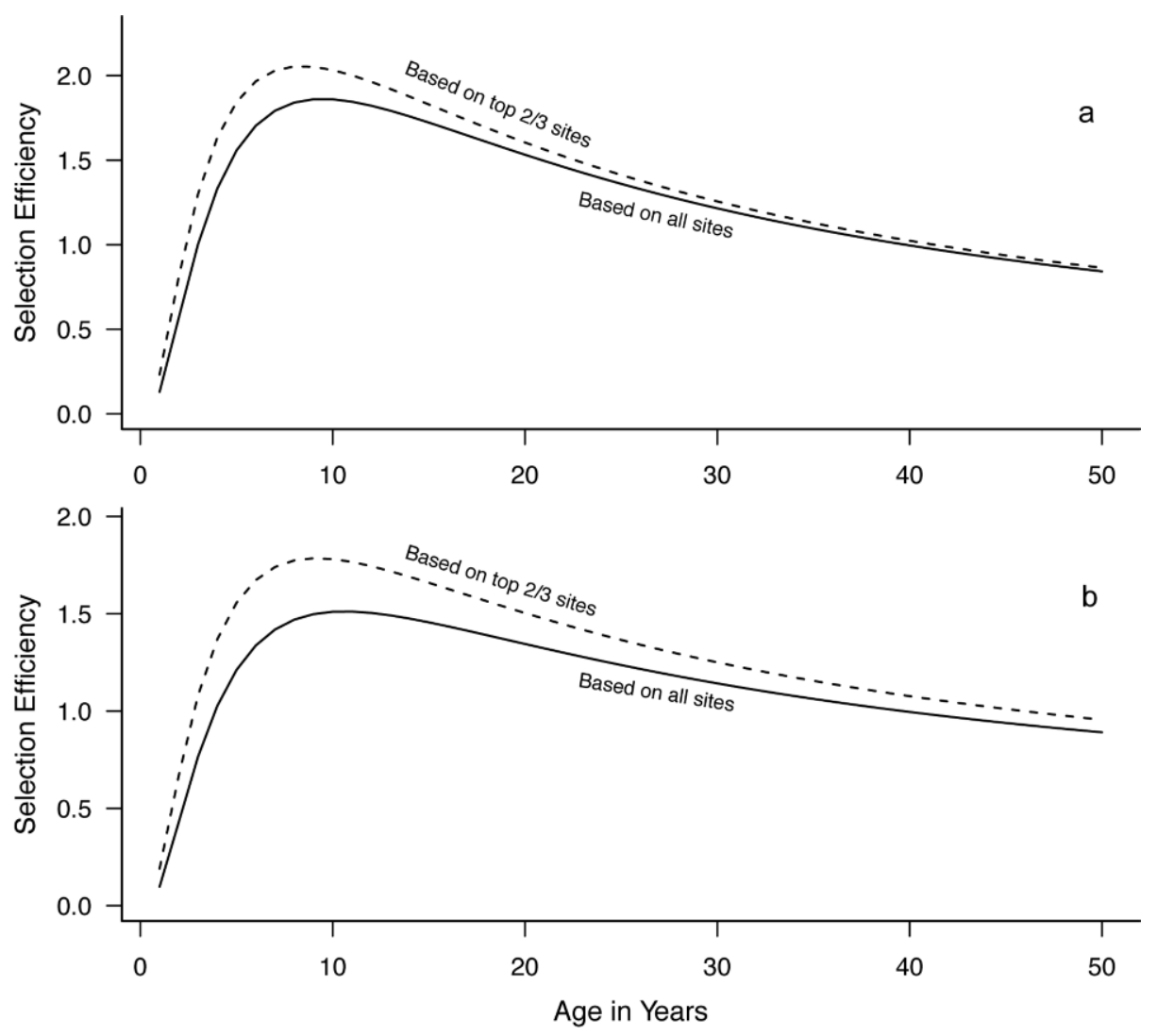

Figure 7. - Efficiencies of early selection on height using gain per year $(Q)$ relative to direct selection on age-50 volume (based on all sites or top 2/3 sites per breeding zone); $a-$ family selection, $b$-within-family selection.

$(Q=1.41), \quad 17(Q=1.50)$, and $22(Q=1.49)$ through indirect family selection on HT_INC, DBH_INC, and VOL_INC, respectively. HT was clearly the best trait for early selection to improve VOL50, as it produced highest genetic gain per year in VOL50 compared to the direct selection on VOL50 itself and had the earliest optimum selection age. The superiority of early selection on HT was obviously due to its higher heritability estimates and stronger juvenile-mature genetic correlations than other traits at early ages. The optimum ages of early family selection on total growth were $4 \sim 11$ years earlier than on the corresponding growth increment traits in general. Within-family selection had the similar patterns as family selection except that optimum selection ages appeared at least 2 years later (Figure $4 b$ and Table 4). It is worth mentioning that all the curves of selection efficiency had broad ranges of near optimum selection ages, which is in line with the observations from other studies on Douglas-fir (e.g., Magnussen and YanchuK, 1993; Johnson et al., 1997).

Using an interest rate $d=6 \%$, the shapes of curves of discounted efficiency $\left(Q^{\prime}\right)$ with age were similar to that of gain per year efficiency $(Q)$, and also had a broad range of selection ages that gave close to optimal relative efficiency (Figure 5). The maximum Q's for VOL50 when selecting on various traits before age 13 were in the following order: HT > VOL > DBH > HT_INC or DBH_INC > VOL_INC. Through family selection, $Q$ ' for
VOL50 when selecting on HT was maximized at 10 years, and that based on $\mathrm{DBH}$ or VOL selection was maximized at 12 or 11 years (Table 4). The optimum ages of family selection based on $Q$ 's were similar to that based on $Q \mathrm{~s}$ (difference $\leq 1$ year). Unlike the selections based on $Q \mathrm{~s}$, however, the optimum selection ages based on $Q$ 's were similar for both family and withinfamily selections.

The discounted efficiency and optimum ages of selection were obviously affected by the interest rate (Figure 6 ). Reducing the interest rate widens the peak of the curve, increases the range of ages which are only slightly sub-optimal, and also makes the optimum age of selection appeared later. For example, changing the interest rate from $2 \%$ to $8 \%$, the optimum age of family selection for VOL50 on HT reduced from 16 years to 8 years.

\section{Effect of tree size on efficiency and optimum age of early selection}

Figure 7 compares the per-year relative efficiencies $(Q)$ for selecting VOL50 based on height growth; using (1) full data set from all sites and (2) data subset from the top $2 / 3$ sites per breeding zone. The average age- 10 height growth for this data subset was about $10 \%$ larger than that for the full data set. It is evident that the optimum ages for VOL50 by selecting early height growth using the data subset were $1 \sim 2$ years earlier than using the full data set. This indicated that the optimum age of 
selection is likely related to tree size at the age of selection, and the sites with bigger trees tended to have earlier optimum ages of selection and higher relative selection efficiency than the sites with smaller trees.

\section{Discussion}

Many researches used age-age correlation models for studying the efficiency of early selection since the 1950's. Until now, it is still the most common approach to determine which trait to select on and when to select, and its success depends on our ability to predict the age trends of heritability and genetic correlations (CHEN et al., 2003; WHITE et al., 2007). Since most published studies were based on measurement data at young ages (less than half rotation), a potential serious weakness of most age-age correlation model-based studies is the built-in reliance of curve trajectory on unverified extrapolations from the restricted growth records to the rotation-age growth (MAGNussen and YANCHUK, 1993). The age trends of these two genetic parameters are also known to vary among populations and traits, and be affected by silvicultural treatments and inter-genotypic competition (Foster, 1989; MAGNUSSEN and YANCHUK, 1993; LAMBETH and DILL, 2001). Thus, there is clearly scope for further documentation. More results, especially those based on the close-to-rotation measurements, are needed to improve our understanding of the age patterns. With the growth data collected from a wide range of ages ( 3 to 41 ) and geographic area (68 test sites), we believe that our study provides new empirical results in the context of Douglas-fir breeding program in the US Pacific Northwest.

Heritability estimates for total growth traits tended to increase with age, which is generally consistent with previous studies on Douglas-fir growth. For examples, JOHNSON et al. (1997) reported an increasing trend in heritability of growth up to age 25 (the oldest age examined) based on 51 test sites in the US Pacific Northwest. DEAN and STONECYPHER (2006) observed that heritability of height growth increased initially then remained relatively stable from age 4 to 17 while heritabilities of stem diameter and volume increased between ages 5 to 10 . Heritability estimates for diameter in this study were generally lower than for height across the ages examined, as observed in some studies on Douglas-fir (KING et al., 1988; AdAMs and Joyce, 1990; DeAn and StoneCYPHER, 2006) and other conifers (e.g., Foster, 1986; GWAZE and BRIDGWATER, 2002; LEE et al., 2002). Such differences further increased with age. This may be partly due to the fact that stand density or inter-genotypic competition tends to affect bole diameter more than it affects height (Husch et al., 1972) and old genetic tests generally had less intensive silvicultural practices (GWAZE et al., 2000). Although heritability estimates showed different age trends among breeding zones, the differences in intercept and slope were fairly small which allowed for drawing a general pattern over the entire region.

Similar to total growth, the heritability estimates for growth increment traits increased with age as well. The increase for HT_INC was almost linear with age, while the increases for DBH_INC and VOL_INC were logarithmic. Relatively large measurement errors are usually expected in DBH_INC and VOL_INC when the trees are very small, which may have resulted in large residual variances and low heritability estimates at very young ages. In a radiata pine study, COTTERILL and DEAN (1988) also found a remarkably consistent trend of increasing heritability of section-area increment over time. KING et al. (1988) reported low heritability estimates for height increment in two coastal Douglas-fir trials, while BORRALHO et al. (1992) found no marked differences between the estimates of heritability from total and incremental measurements in a eucalyptus study.

The age-age genetic correlation for total growth traits observed in this study fitted LAMBETH's (1980) model surprisingly well, despite data being collected from multiple independent breeding zones. The models' $R^{2}$ were almost twice as high as that reported from JoHNSON et al. (1997). The superiority of using $L A R^{2}$ as a predictive variable for age-age genetic correlation as reported in loblolly pine by LAMBETH and DiLL (2001) was not evident in this study. Although LAMBETH's (1980) model has been successfully used to describe the age-age genetic correlation for growth traits in many studies (e.g., McKeand, 1988; KInG and Burdon, 1991; JoHnson et al., 1997; GWAZE et al., 2000) as well as in this study, it did not seem to fit growth increment traits well. In the present study, we found that a log-linear model using $L A R^{3}$ as a predictor $\left(\ln (r)=a+b \cdot L A R^{3}\right)$ generally gave the best fit for the increment traits.

Age-age genetic correlations between height at various ages and volume at rotation age were higher than the corresponding correlations between diameter and rotation-age volume before ages $20 \sim 25$; after that point the reverse was true. This is similar to the pattern found in a loblolly pine study by GWAZE and BRIDGWATER (2002).

Age-age genetic correlations for total growth traits could be upwardly biased due to the "built-in" autocorrelation arising from the fact that the same tree is measured at multiple ages (i.e., the height at age 10 is part of the height at age 20). As pointed out by LAMBETH et al. (1983) and MCKINLEY and LowE (1986), because growth traits are cumulative, the magnitude of age-age genetic correlations reflect not only genetic effects, but also the amount of early growth in the mature stage. BORRALHO et al. (1992) believed that the major advantage of using increment traits is that it removes the cumulative nature of growth traits from the analysis and, therefore, can provide a better indication of age patterns of genetic parameters. Such statement did not, however, consider the fact that the growth increments of trees are usually not observed directly in the field but calculated as the differences of total growth measurements. Assuming height increment $\Delta h_{t}$ is calculated as $\Delta h_{t}=h_{t+1}-h_{t}$ where $h_{t}$ is the height at age $t$, then the successive height increments $\Delta h_{t}=h_{t+1}-h_{t}$ and $\Delta h_{t+1}=h_{t+2}-h_{t+1}$ are not statistically independent because they both depend on $h_{t+1}$. Thus, although we found that growth increment traits had lower age-age correlations than total growth traits at least at early ages in this study, it does not nec- 
essarily suggest that autocorrelation had a significant influence on the age-age correlations observed in total growth traits.

Early selection is preferred for most commercial tree species with long generation intervals, as it results in an increased gain per unit of time through reduced generation intervals and may lead to reduced testing costs (MAGNussen, 1988). Traditionally, the optimum selection age has been defined as the selection age when average annual genetic gain towards the breeding objective is maximized (KANG, 1985; GWAZE et al., 1997). In this study, the optimum selection ages were examined for both family and within-family selection using bole volume at rotation age (i.e., 50yr) as the selection criterion. For family selection, selection at juvenile ages (i.e., 9 for height, 13 for diameter, and 11 for volume) resulted in the greatest correlated per-year gains in rotation volume. Similar results were obtained for within-family selection except that the optimum selection ages were $2 \sim 4$ years later than that from family selection, i.e., 11 for height, 15 for diameter and volume. These suggested optimum ages are close to the current routine assessment ages in the second-cycle Douglas-fir cooperative breeding programs in the US Pacific Northwest. These results were also consistent with those of JoHNSON et al. (1997) in general, although the study by JoHNSON et al. (1997) examined the optimum ages of early selection based on younger data (i.e., age $\leq 25$ ) and used heightheight and diameter-diameter prediction models only due to limitation of data availability. DEAN and STONECYPHER (2006) proposed earlier optimum ages (7 8 years) for improving mature volume based on juvenile height through mass selection; this may have been due to their selection criterion being age-17 volume and data collected on a few fast-growing sites. In a study using stochastic simulation based on four progeny test in BC, MAGNUSSEN and YANCHUK (1993) indicated that the risk for making family selection before age 15 in Douglas-fir progeny tests was low when there is at least 20 trees per family. Also similar to JoHNSON et al. (1997) and MAGNussen and YANCHUK (1993), we confirmed that there were broad ranges of near optimum selection ages for each selection scheme.

For both family and within-family selections, our results indicated early selection based on height was always more efficient and had earlier optimum selection ages than on diameter or volume. This is in line with the results reported from several studies on Douglas-fir (JOHNSON et al., 1997; DEAN and STONECYPHER, 2006) and other species (e.g., GWAZE and BRIDGWATER, 2002). Others have found that the most effective growth traits to use in making volume selections would be juvenile diameter (e.g., KING et al., 1988 for Douglas-fir) or volume (e.g., XIANG et al., 2003 for loblolly pine). The results found in the present study are largely expected given the fact that height had the highest heritability estimates at juvenile ages and the strongest juvenilemature genetic correlations.

Unlike in the area of growth modeling where growth increments are often used to project individual tree growth and then aggregate these attributes to a stand level (DALE et al., 1985), most studies on the efficiency of early selection in literature were based on total growth instead of increments (see BORRALHO et al., 1992). Results from the present study indicated that genetic gains per year in rotation-age volume based on height increment never exceeded those based on total height during the range of ages examined. The optimum ages of selection on height increment appeared five years later than that on total height. Family selection based on diameter increment or volume increment achieved higher genetic gains in rotation-age volume than on total diameter only after 13 or 20 years, with the optimum age being 17 or 22 years. Thus, early selection based on juvenile total height is generally recommended for the operational Douglas-fir breeding programs, as it yielded the highest selection efficiency and earliest optimum age of selection among all the total growth and increment traits.

With interest rate $(d)=6 \%$, the optimum ages of selection derived from the discounted analysis were similar to that based on gain per year. Increasing $d$ reduced the optimum age of selection. For example, the optimum age of family selection on height for rotationage volume reduced from 16 to 8 years when $d$ was increased from $2 \%$ to $8 \%$. Whilst an interest rate of $6 \%$ has been used in this study, published discussion on choices of interest rate has been considerable. For examples, $d=5 \%$ was used for Scots pine (JANSSON et al., 2003), slash pine (WHITE and HodGe, 1992) and eucalyptus (GREAVES et al., 2003); and 4 8\% for Douglas-fir (JoHnson et al., 1997). White and HodGe (1992) recommended $5 \sim 6 \%$ interest rate for private forestry investment in the US.

It has been observed that optimum selection age may be related to tree size rather than tree age per se. CoTTERILL and DEAN (1988) concluded absolute size to be more important than age in determining the optimum age in radiata pine. Results obtained for Scots pine by HAAPANEN (2001) and JANSSON et al. (2003) suggested that the optimum selection age occurred later for slow growing than for fast growing trials. A similar tendency was also found in this study (Figures 7). Based on the regression of mean height growth against measurement age at breeding zone level using the current data set (i.e., $H T=-3.4881+0.8415 \cdot$ age; $R^{2}=0.97$; results not shown), family selection seems to be optimal at average height of $4 \sim 5$ meters, which is similar to the height of 4.5 to 5.5 meters suggested by Dean and Stonecypher (2006) for mass selection. Within-family selection appears to be optimal at average height of $5.8 \sim 6.6$ meters.

While selection for growth rate is often of primary concern, other traits like wood quality (e.g., wood stiffness), form traits (e.g., forking, ramicorn branches and stem sinuosity), as well as the ability to survive late spring frosts, early fall frosts, cold winter temperatures and grow successfully through a fairly long rotation $(40 \sim 60$ yrs) are also important to growers of Douglas-fir in the US Pacific Northwest. These considerations may result in delaying selection beyond the optimum indicated in this work. 


\section{Conclusion}

Maximum genetic gain in rotation-age (i.e., 50yr) bole volume per year could be obtained by selecting on total height around age 9 via family selection when trees were 4 to 5 meters in height. Optimum age for withinfamily selection on height is expected to be about 2 years later. Discounted gain was optimized at age-10 when selecting on total height using an interest rate of $6 \%$. Early selection on increment traits was less efficient than on total height due to their relatively low heritability estimates at young ages and low juvenile-mature genetic correlations. Within a given breeding zone, the optimum selection ages for slow-growing trials are later than for fast-growing trials.

\section{Acknowledgements}

Trial establishment and measurements to age-15 were funded by many companies and agencies through firstgeneration testing cooperatives in the US Pacific Northwest. Data subsequent to age-15 were mostly provided by Eugene-District BLM (RICH KELLY), Starker Forests Inc. (FRED PFUND) and Stimson Lumber Company (MARGARET BANKS). The Northwest Tree Improvement Cooperative (NWTIC) funded this research work, as well as the measurement of all Vernonia program after age-15 and a couple of the other programs at age-20.

\section{References}

Adams, W. T. and D. G. Joyce (1990): Comparison of selection methods for improving volume growth in young coastal Douglas-fir. Silvae Genet. 39: 219-226.

BAKER, R. J. (1986): Selection Indices in Plant Breeding. CRC Press, Boca Raton, FL.

Borralho, N. M. G., P. J. Kanowski and P. P. Cotterill (1992): Genetic control of growth of Eucalyptus globulus in Portugal. I. Genetic and phenotypic parameters. Silvae Genet. 41: 39-45.

Bouvet, J. M., P. Vigneron, E. Villar and A. SAya (2007): Determining the optimal age for selection by modelling the age-related trends in genetic parameters in Eucalyptus hybrid populations. Silvae Genet. 58: 102-112.

BRUCE, D. and D. J. DeMars (1974): Volume equations for second-growth Douglas fir. U.S. Dep. Agric. For. Serv., Pac. Northwest For. Range Exp. Stn., Res. Note 239.

Chen, X. Y., B. Hawkins, C. Y. XIE and C. C. YInG (2003): Age trends in genetic parameters and early selection of lodgepole pine provenance with reference to the Lambeth model. For. Genet. 10: 249-258.

CoRnelius, J. (1994): Heritabilities and additive genetic coefficients of variation in forest trees. Can. J. For. Res. 24: 372-379.

CotTerill, P. P. and C. A. DEAN (1988): Changes in genetic control of growth of radiata pine to 16 years and efficiences of early selection. Silvae Genet. 37: 138-146.

CotTERILL, P. P. and J. W. JAMES (1984): Number of offspring and plot sizes required for progeny testing. Silvae Genet. 33: 203-209.

Dale, V. H., T. W. Doyle and H. H. Shugart (1985): A comparison of tree growth models. Ecol. Model. 29: 145-169.

Dean, C. A. and R. W. Stonecypher (2006): Early selection of Douglas-fir across south central coastal Oregon, USA. Silvae Genet. 55: 135-141.
Dickerson, G. E. and L. N. HAZEL (1944): Effectiveness of selection on progeny performance as a supplement to earlier culling in live stock. J. Agric. Res. 69: 459-476.

FALCONER, D. S. and T. F. C. MACKAY (1996): Introduction to quantitative genetics. Longman, New York.

FosteR, G. S. (1986): Trends in genetic parameters with stand development and their influence on early selection for volume growth in loblolly pine. For. Sci. 32: 944-959.

Foster, G. S. (1989): Inter-genotypic competition in forest trees and its impact on realized gain from family selection. P. 21-35. In: Proc. $20^{\text {th }}$ So. For. Tree Improv. Conf., Charleston, SC.

Gilmour, A. R., B. J. Gogel, B. R. Cullis and R. Thompson (2009): ASReml User Guide Release 3.0. NSW Department of Industry and Investment, Harpenden, UK.

Greaves, B. L., N. M. G. Borralho and C. A. Raymond (2003): Early selection in eucalypt breeding in Australia - optimum selection age to minimise the total cost of kraft pulp production. New For. 25: 201-210.

Gwaze, D. P. and F. E. BRIDGWATER (2002): Determing the optimum selection age for diameter and height in loblolly pine. For. Genet. 9: 159-165.

Gwaze, D. P., F. E. Bridgwater, T. Byram, J. A. Woolliams and C. G. Williams (2000): Predicting age-age genetic correlations in tree breeding programs: a case study of Pinus taeda L. Theor. Appl. Genet. 100: 199-206.

Gwaze, D. P., J. A. Wodliams and P. J. Kandowski (1997): Optimum selection age for height in Pinus taeda L. in Zimbabwe. Silvae Genet. 46: 358-365.

HAAPANEN, M. (2001): Time trends in genetic parameter estimates and selection efficiency for Scots pine in relation to field testing method. For. Genet. 8: 129-144.

Husch, B., C. I. Miller and T. W. Beers (1972): Forest Mensuration. John and Sons, New York.

JANSSON, G., B. LI and B. HANNRUP (2003): Time trends in genetic parameters for height and optimal age for parental selection in Scots pine. For. Sci. 49: 696-705.

Johnson, G. R., R. A. Sniezko and N. L. MANDEL (1997): Age trends in Douglas-fir genetic parameters and implications for optimum selection age. Silvae Genet. 46: 349-358.

KANG, H. (1985): Juvenile selection in tree breeding: Some mathematical models. Silvae Genet. 34: 75-84.

KING, J. N. and R. D. BURDON (1991): Time trends in inheritance and projected efficiencies of early selection in a large 17-year-old progeny test of Pinus radiata. Can. J. For. Res. 21: 1200-1207.

KInG, J. N., F. C. YeH and J. C. H. Heaman (1988): Selection of growth and yield traits in controlled crosses of coastal Douglas-fir. Silvae Genet. 37: 158-164.

LAmbeth, C. and L. A. Dill (2001): Prediction models for juvenile-mature correlations for loblolly pine growth traits within, between and across sites. For. Genet. 8: 101-108.

LAMBETH, C. C. (1980): Juvenile-mature correlations in Pinaceae and implications for early selection. For. Sci. 26: $571-580$.

Lambeth, C. C., J. P. van Buijtenen, S. D. Duke and R. B. McCullough (1983): Early selection is effective in 20year-old genetic tests of loblolly pine. Silvae Genet. 32: 210-215.

LeE, S. J., J. Woolliams, C. J. A. Samuel and D. C. MalCOLM (2002): A study of population variation and inheritance in Sitka spruce. II. Age trends in genetic parameters for vigour traits and optimum selection ages Silvae Genet. 51: 55-65. 